\title{
Dynamic Processes in a Machine-Tool at High-SPEED MACHINING
}

\author{
OMELCHAK, A.G. \& FECAK, S.I. \& IDRISOVA, U.V.
}

Abstract: An experimental research of HSM turning of parts made of the titanium alloy VT9 was conducted. The dynamic processes during turning of the titanium alloy VT9 with a tungsten carbide VK6OM cutter were analyzed.

Key words: Self-excited vibration, dynamic response, cutting process.
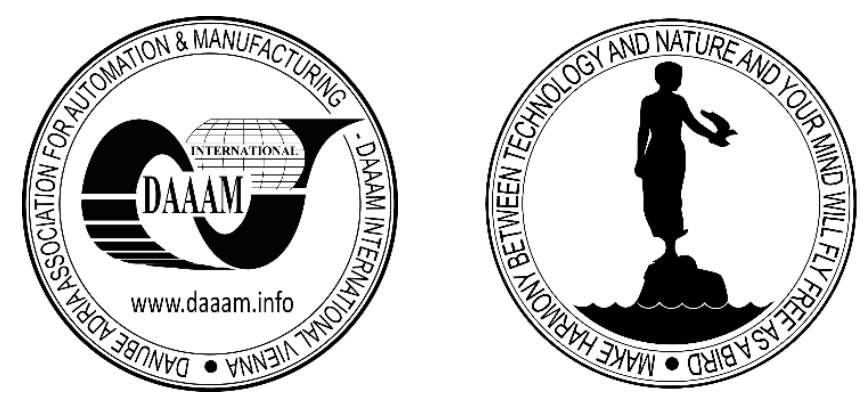

Authors' data: Bachelor of Science Omelchak, A.G; PhD. Assoc. Prof. Fecak, S.I. ; $\mathrm{PhD}$. Assoc. Prof. Idrisova, U.V., Ufa State Aviation Technical University, K. Marks 12, 450008, Ufa, Russian Federation, alexisom@yandex.ru, format_invest@mail.ru, yu.v.idrisova@mail.ru

This Publication has to be referred as: Omelchak, A[leksandr]; Fecak, S[.I.] \& Idrisova, U[.V.] (2016). Dynamic Processes in a Machine-Tool at High-Speed Machining, Chapter 16 in DAAAM International Scientific Book 2016, pp.175-182, B. Katalinic (Ed.), Published by DAAAM International, ISBN 978-3-902734-09-9, ISSN 1726-9687, Vienna, Austria

DOI:10.2507/daaam.scibook.2016.16 


\section{Introduction}

There is a certain problem that can be found performing high-speed machining, the highest accuracy and performance of a metal cutting machine can be reached on specific combinations of machined material, cutting tool and cutting parameters.

To maintain reliable performance of modern high-speed metal cutting machines it is necessary to perform research of dynamic characteristics of metal cutting machines.

Modern construction materials (stainless steel, high-temperature steel, and titanium) are widely used in machine building and aircraft building. These materials have high-end service property but are intractable.

The aim of the research conducted is the development of a method to assess influence of dynamic processes of the metal cutting machine elastic system.

The method can be applied by resolving the following tasks:

- examine dynamic processes of a metal cutting machine (self-induced vibrations and forced vibrations)

- examine cutting tool vibrations and workpiece vibrations during machining and locate sources of vibrations caused by machining.

- locate the main source of vibrations, most affecting of the tool wear of a cutting tool.

An experimental research of the metal cutting machine elastic system was performed. The metal cutting machine Mori Seiki model NL1500SY was used during turning of the titanium alloy VT9 $(\mathrm{Ti}=86.15 \%-89.9 \%, \mathrm{Al}=5.8 \%-7 \%, \mathrm{Mo}=2.8 \%-3.8 \%$, $\mathrm{Zr}=1 \%-2 \%$ and others elements). Turning was performed with a tungsten carbide VK6OM (WC $=92 \% ; \mathrm{TaC}=2 \%, \mathrm{Co}=6 \%$ ) cutter. The metal cutting machine has a turret head with three degrees of freedom $(\mathrm{X}, \mathrm{Y}, \mathrm{Z})$ and two direct drive spindle motors. A module USB system NI CompactDAQ from National Instrument (USA) was used to monitor signals of vibration sensors. The monitoring system consists of a NI cDAQ9172 chassis as an analog-digital converter/digital-analog converter and a 4 channels, 24 bits analog input module NI 9233 with sampling rate of $50 \mathrm{kHz} / \mathrm{channel}$. NI LabVIEW 8.5 software was used to monitor and record data. LabVIEW is a systemdesign platform and development environment for a visual programming language from National Instruments.

Natural frequencies were measured by hit-tests of the metal cutting machine elements: turret head, spindle head, spindle unit, bearings of $\mathrm{X} / \mathrm{Y}$ axes ball screws, $\mathrm{X} / \mathrm{Y}$ axes guide rails. To measure natural frequencies of the spindle sensors were mounted on the front end of the spindle, vibrations were measured on the X/Y/Z axes. Hit-tests impacts were applied in the direction of the $\mathrm{Z}$ axis, to cause higher amplitude in this direction.

Four natural frequencies of the direct drive spindle motors were found: $330 \mathrm{~Hz}$ and $400 \mathrm{~Hz}$ - electric components (stator winding and stator lamination), $700 \mathrm{~Hz}-$ outer rings of front end bearings, $820 \mathrm{~Hz}$ - inner rings of front end bearings.

The research of forced vibrations of metal cutting machine drives was performed on run idle. The following sources of vibrations can be found in drives: disbalance of the spindle; manufacturing defects of drives, bearings, ball screws and etc. 
With the change of spindle speed (400 - $6000 \mathrm{rev} / \mathrm{min})$ amplitude peaks were shifting that indicates the presence of a forced component that reveals itself at the frequency multiple to the frequency of the drive.

The maximum values of amplitudes were observed at $800 \mathrm{rev} / \mathrm{min}$ and 1500 rev/min, which correspond to the character and type of electromagnetic vibration phenomena in the direct drive spindle motor.

Finish machining is the most responsible part of machining in terms of the quality and accuracy of the machined surface. In this research taking into account recommendations (Gurevich et al., 1986), cutting parameters are the following: feed $S$ $=0.1 \mathrm{~mm} / \mathrm{rev}$, cutting depth $t=0.5 \mathrm{~mm}$. The cutting parameters were chosen to obtain small chip thickness during high-speed machining.

Cutting parameters are presented in Table 1 .

\begin{tabular}{|c|c|c|c|c|c|}
\hline № & $\begin{array}{c}\text { Cutting } \\
\text { speed } V, \\
\mathrm{~m} / \mathrm{min}\end{array}$ & $\begin{array}{c}\text { Diameter } \\
D, \text { мM }\end{array}$ & $\begin{array}{c}\text { Rotation of the spindle } \\
n, \mathrm{rev} / \mathrm{min}\end{array}$ & $\begin{array}{c}\text { Cutting length } \\
L, \mathrm{~mm}\end{array}$ & $\begin{array}{c}\text { Cutting } \\
\text { path } l, \\
\mathrm{~mm}\end{array}$ \\
\hline 1 & 20 & 16.5 & 386 & 70 & 36285 \\
\hline 2 & 40 & 17.5 & 728 & 70 & 38484 \\
\hline 3 & 60 & 17.5 & 1091 & 70 & 38484 \\
\hline 4 & 100 & 18.5 & 1721 & 70 & 40683 \\
\hline 5 & 150 & 18.5 & 2581 & 70 & 40683 \\
\hline 6 & 200 & 19.5 & 3265 & 70 & 42882 \\
\hline 7 & 250 & 19.5 & 4081 & 70 & 42882 \\
\hline 8 & 300 & 20.5 & 4658 & 70 & 45081 \\
\hline 9 & 350 & 20.5 & 5435 & 70 & 45081 \\
\hline 10 & 400 & 21.5 & 5922 & 60 & 40526 \\
\hline
\end{tabular}

Tab. 1. Cutting parameters of the vibration research during turning of the titanium alloy VT9 with a tungsten carbide VK6OM insert.

The research data are a set of the amplitude-frequency characteristics (values of vibration velocity amplitudes in the band $0-25 \mathrm{kHz}$ ) that were obtained during monitoring and were recorded with the monitoring system. In each test amplitudefrequency response was recorded for $0.2 \mathrm{sec}$.

During machining at cutting speed $V=60 \mathrm{~m} / \mathrm{min}$ data shown that at the same vibration frequency the amplitude of vibrations changing periodically (Fig. 1).

There was a vibration amplitude peak at the frequency $320 \mathrm{~Hz}$ for each moment of monitoring time.

The analysis of that dependence (Fig. 2) has shown a cyclic changing of vibration amplitude that is typical to the process of the development of self-excited vibrations during machining of the titanium alloy VT9 with a tungsten carbide VK6OM insert. 
Omelchak, A.; Fecak, S. \& Idrisova, U.: Dynamic Processes in a Machine-Tool at ...

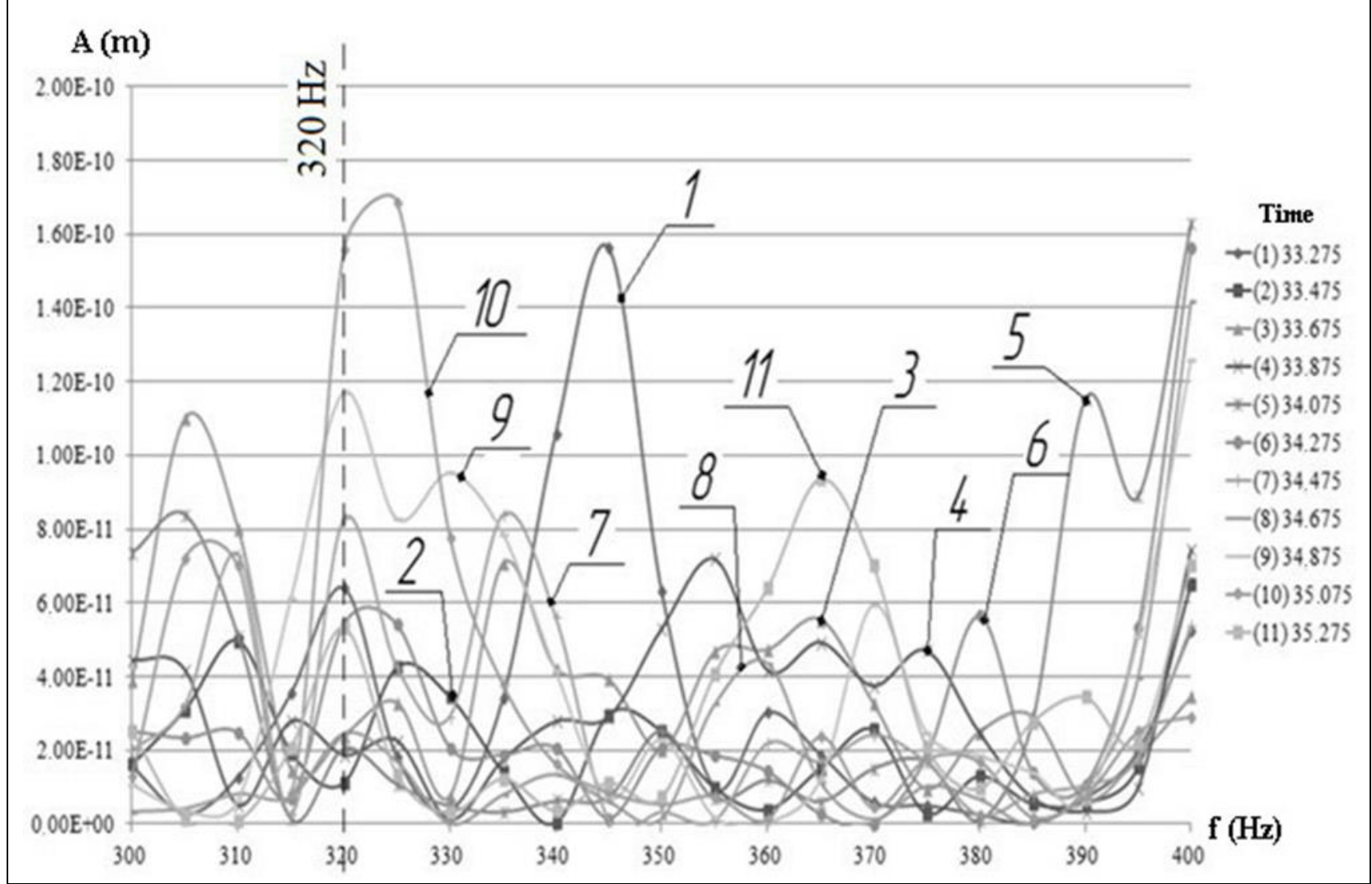

Fig. 1. Amplitude of vibrations at different moments of time in the frequency band $300-400 \mathrm{~Hz}$

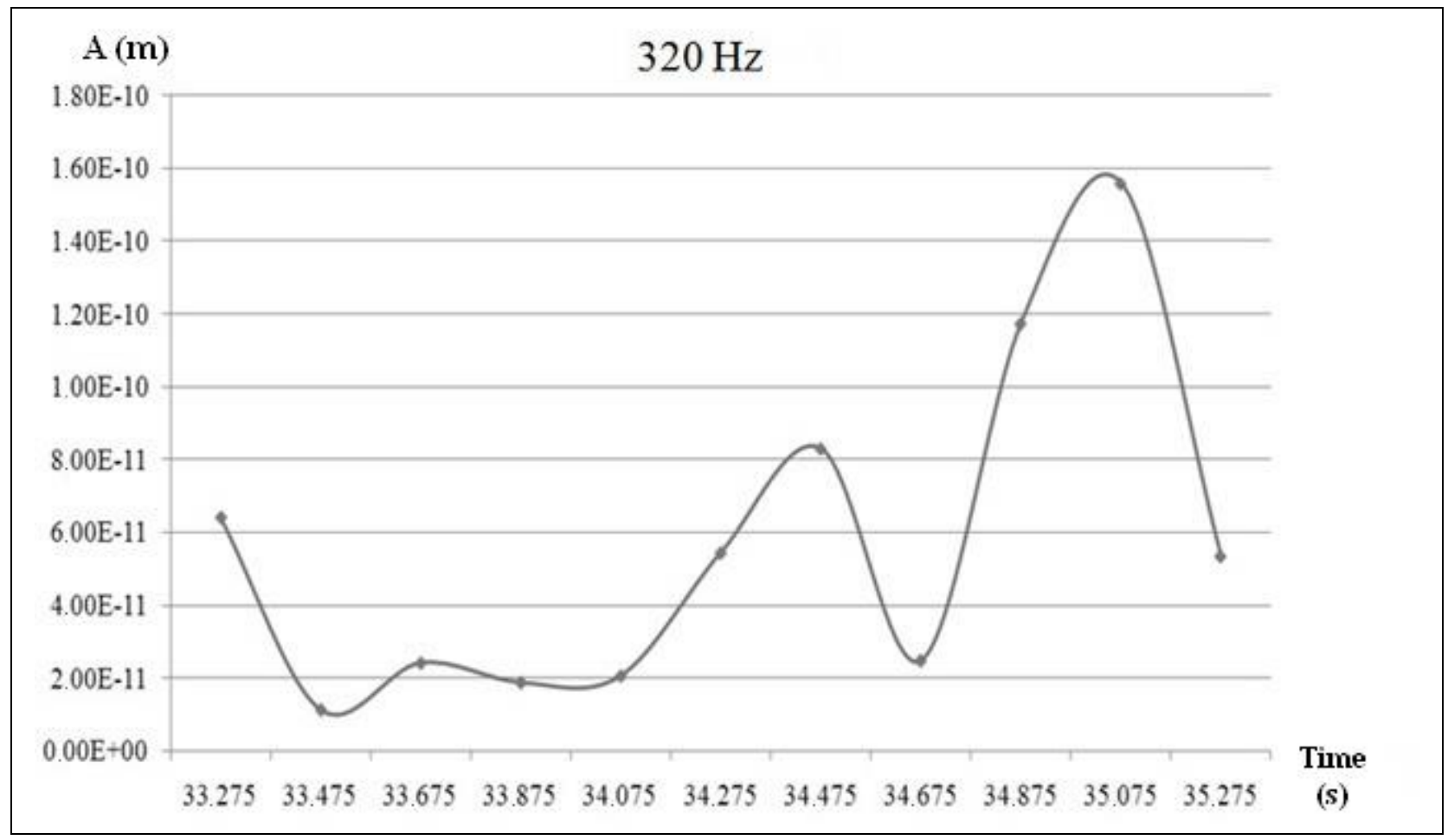

Fig. 2. Changing of amplitude of vibrations at $320 \mathrm{~Hz}$ frequency

Every technological process has its optimal level of self-excited vibrations (cyclic vibrations at the cutting zone) at which the tool life will be the maximum. That can be explained with the following explanation (Postnov et al., 2015) - self-excited 
vibrations induced during machining as well as forced vibrations induced by the metal cutting machine system lead to more simple plastic strain, decreasing of the friction coefficient of the rake face and the flank face of a cutting tool, decreasing of the cutting force and thus it all lead to decreasing of intensity of the tool wear and increasing of the tool life. From the other hand cyclic loading of the tool during increasing of intensity of self-excited vibrations leads to the fatigue failure of the tool-chip contact zone and the tool-workpiece contact zone of a cutting tool. That is why at some level of self-excited vibrations the tool life is decreasing rapidly. The result of these opposite factors is an extreme dependence. In the band of low amplitudes positive influence of self-excited vibrations prevails that can ease the plastic strain process, in the band of high amplitudes prevails the fatigue failure of the contact layers of the tool material. If compare both research results, the research of machining improvement by using forced low frequencies and ultrasound frequencies at the cutting zone and the research of selfexcited vibrations, a common dependence can be found, that was presented at the article (Postnov et al., 2015). Fig. 3 shows the amplitude values of forced vibrations of correspond frequencies. During turning of the titanium alloy VT9 with the tungsten carbide VK6OM dependencies of vibration velocity $A$ from cutting tool frequency $f$ were obtained.

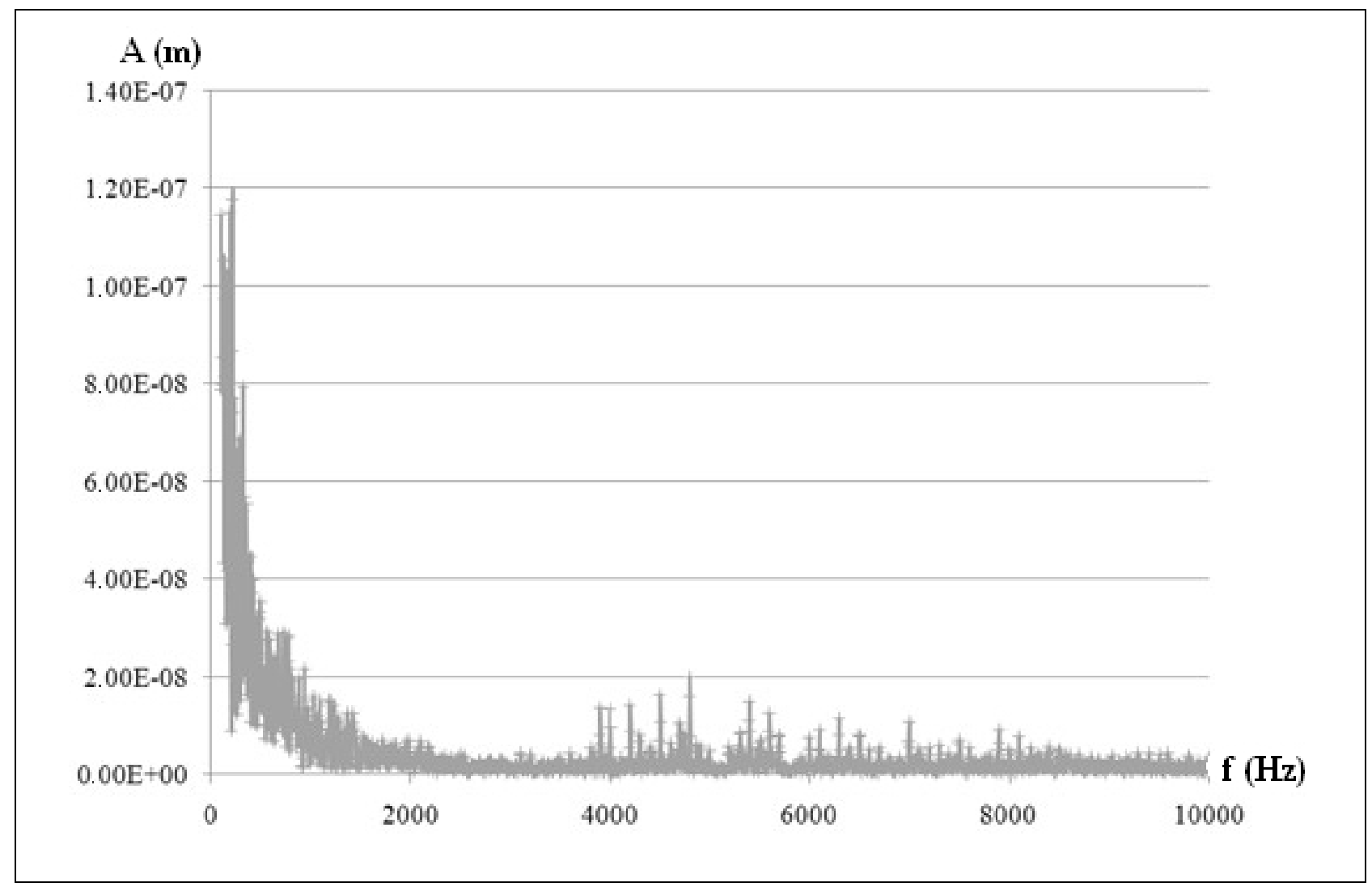

Fig. 3. Amplitude-frequency response of the cutting process

Fig. 4. shows a typical spectral dependence vibration velocity-frequency at the cutting speed $60 \mathrm{~m} / \mathrm{min}$. That dependency is typical at any cutting speed. 
Omelchak, A.; Fecak, S. \& Idrisova, U.: Dynamic Processes in a Machine-Tool at ...

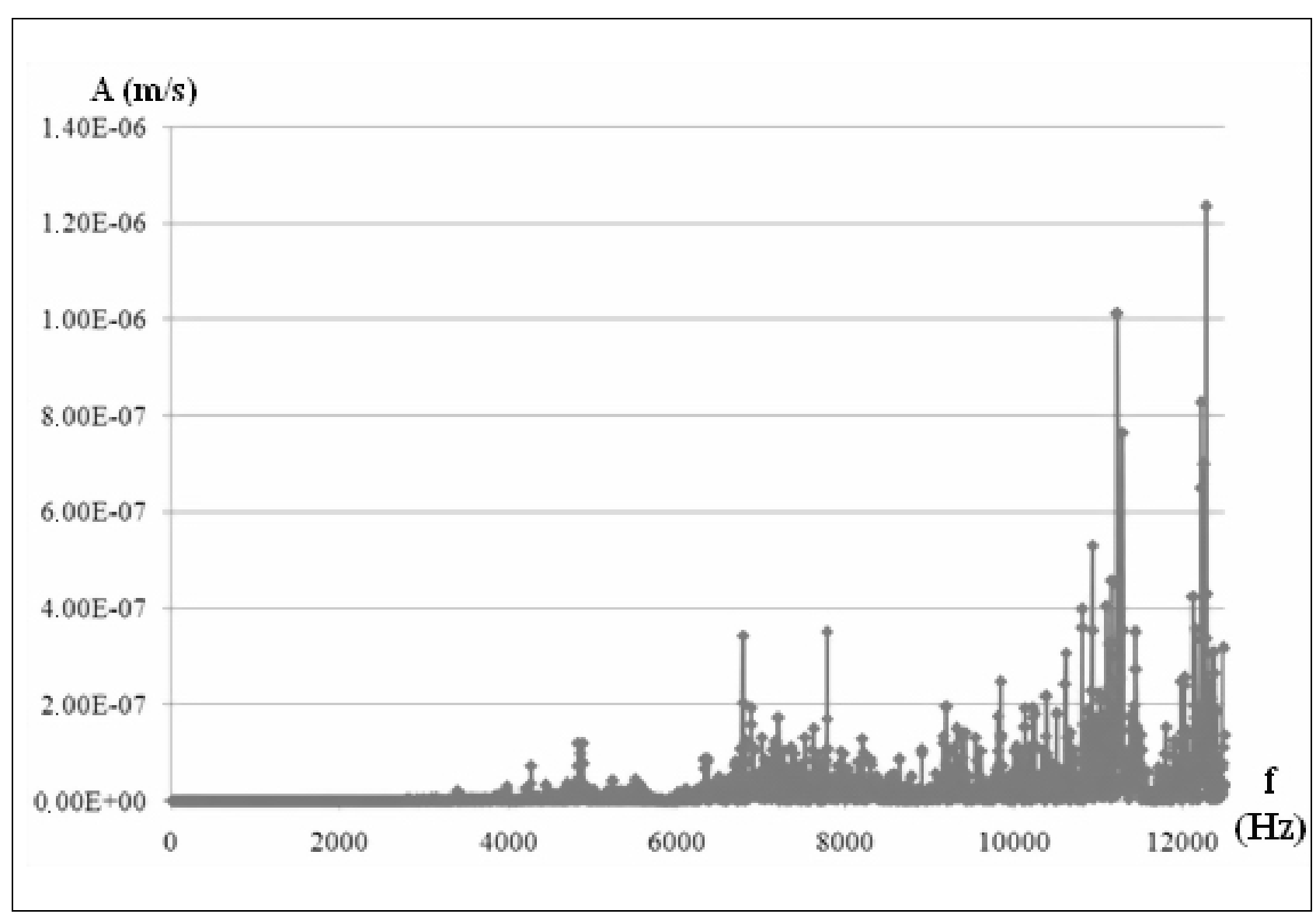

Fig. 4. Typical spectral dependence of vibration velocity-frequency (at cutting speed $60 \mathrm{~m} / \mathrm{min}$ )

The analysis of the influence of amplitude of vibrations and cutting speed on the intensity of the tool wear (tungsten carbide VK6OM) during turning of the titanium alloy VT9 (Fig. 5) has shown that there is a critical value of the intensity of vibrations, when the critical value level is high then the intensity of the tool wear is being increased abruptly. It was determined (Fig. 6) that the amplitude of vibrations has the maximal value at the cutting speed that corresponds to the minimal intensity of the tool wear. 


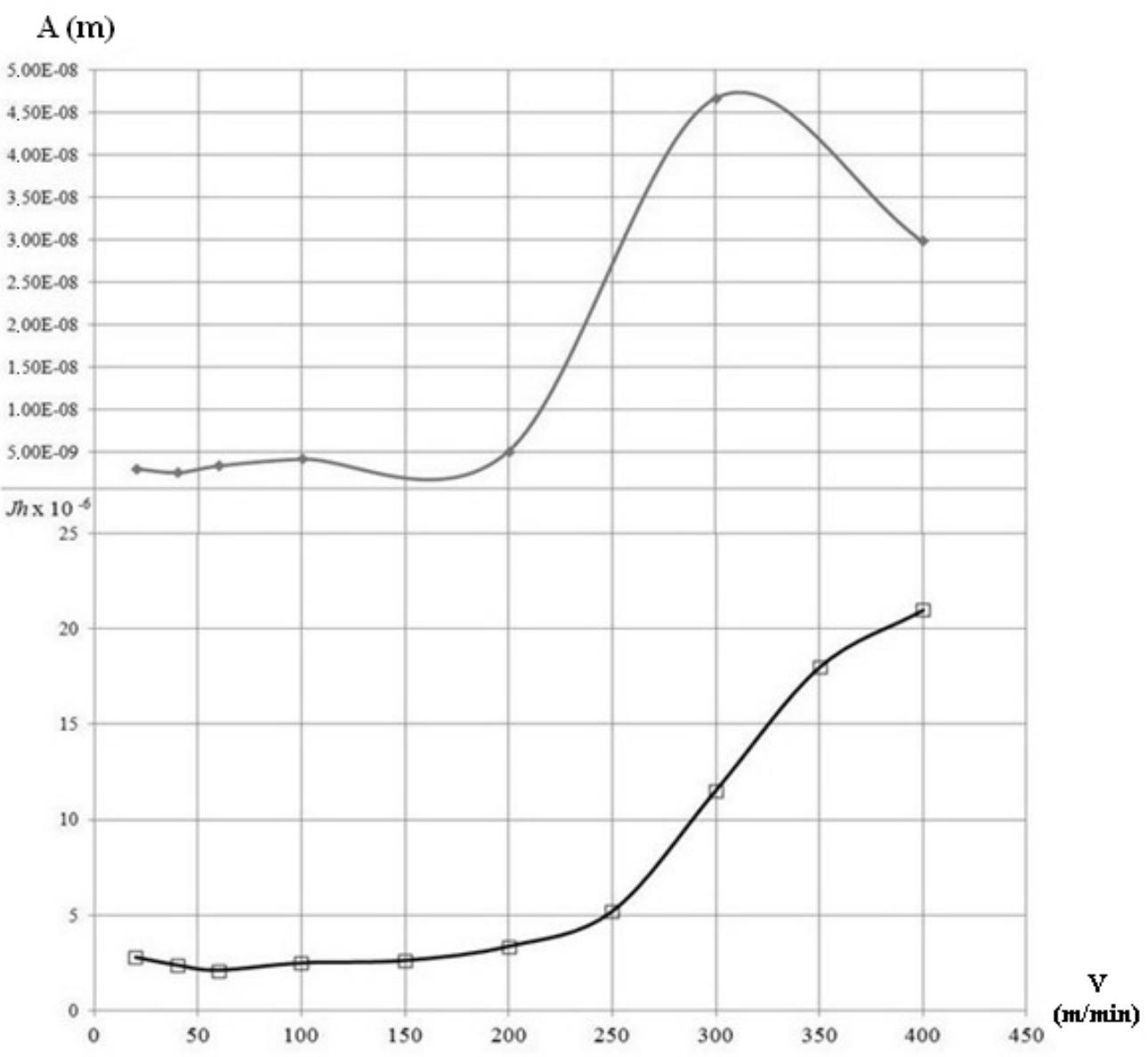

Fig. 5. The influence of amplitude of vibrations and cutting speed on the tool wear (tungsten carbide VK6OM) during turning the titanium alloy VT9, $J h$ - the intensity of the tool wear.

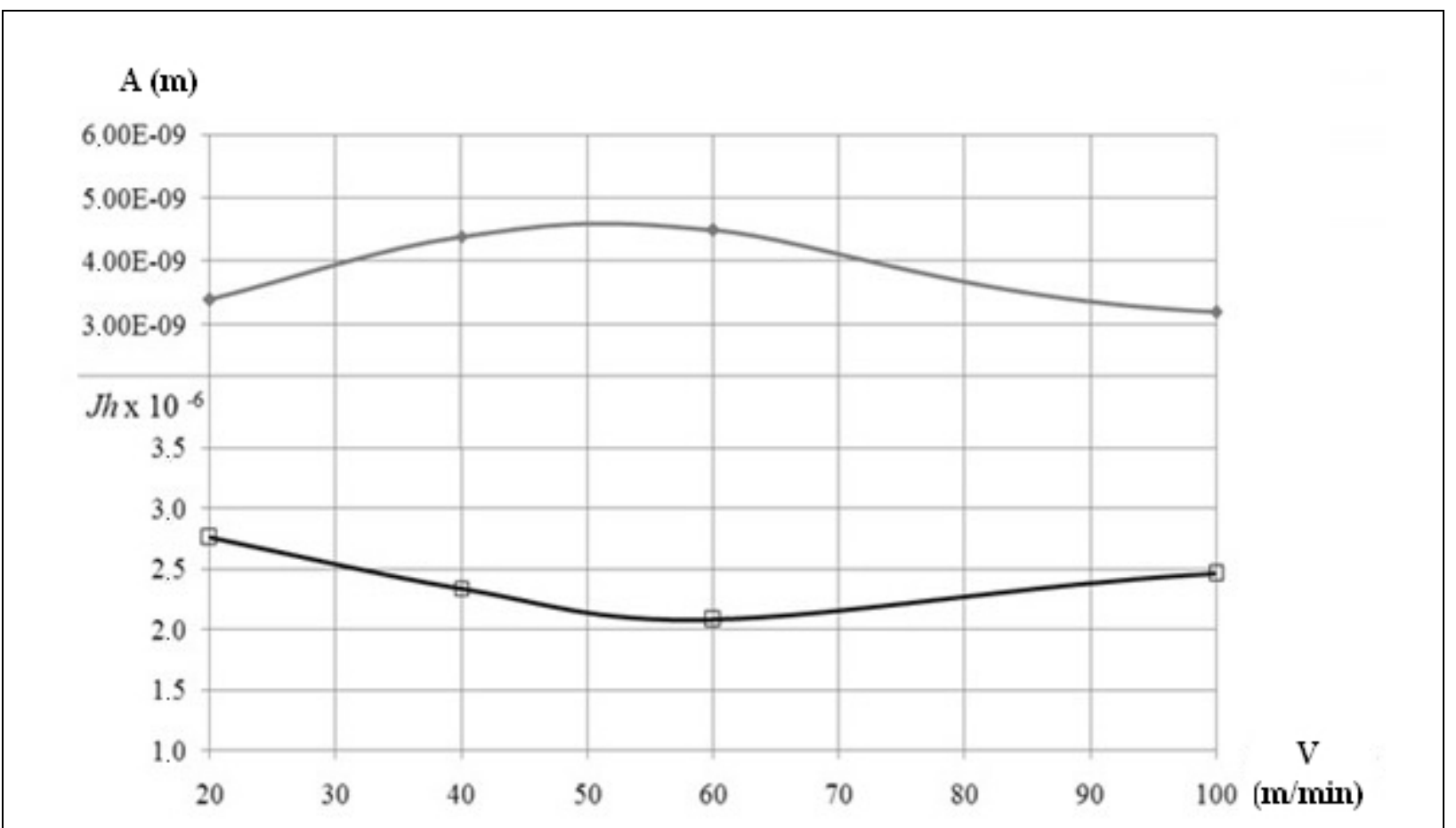

Fig. 6. The influence of amplitude of vibrations and the cutting speed on the intensity of the tool wear (tungsten carbide VK6OM) during turning of the titanium alloy VT9. 
Omelchak, A.; Fecak, S. \& Idrisova, U.: Dynamic Processes in a Machine-Tool at ...

\section{Conclusion}

1. Self-excited vibrations and forced vibrations of elements of the metal cutting machine MORI SEIKI NL1500 were observed. The data obtained can be used to recommend cutting parameters and suggest improvements of the structure of the metal cutting machine.

2. The tool wear intensity analysis taking into account the dynamic of the cutting process allows us to increase HSM productivity.

3. The amplitude responses obtained and dependencies found can be used to forecast the quality of machined surfaces.

\section{References}

V. V. Postnov, Yu. V. Idrisova and S. I. Fetsak. Influence of Machine-Tool Dynamics on the Tool Wear. Russian Engineering Research Vol. 35, No. 12, 2015, p. 936.

Gurevich, Ya.L., Gorokhov, N.V., Zakharov, V.I., et al., Rezhim rezaniya trudnoobrabatyvaemykh materialov: Spravochnik (Cutting Conditions for Hard-ToWork Materials: A Handbook), Moscow: Mashinostroenie, 1986. 